\title{
Stress-Related Changes in Toddlers and Their Mothers Following the Attack of September 11
}

Anne Conway
Columbia University

\author{
Michael J. MacKenzie \\ Columbia University
}

\author{
Susan C. McDonough \\ University of Michigan
}

\author{
Chantal Follett and Arnold Sameroff \\ University of Michigan
}

\begin{abstract}
Unlike other forms of disaster, terrorism is not confined to a particular place or time, and recent evidence indicates that the 9/11 terrorist attack was a significant macrolevel stressor affecting the health and mental health of United States citizens. No studies, however, have reported symptoms in toddlers and their mothers both before and after the attacks. To address this gap, we examined the effects of the 9/11 terrorist attacks on mothers and their 33-month-old toddlers. The attacks occurred during data collection at 33 months of a longitudinal study. Thirty-three-month-old toddlers and mothers who were assessed after the attacks were compared with those assessed before the attacks. When changes were examined from a previous wave of data collected at 15 months, those in the after-attack group showed poorer health, lower child acceptance, and marginally more anxiety, and their toddlers cried more and slept less, whereas the beforeattack group showed no changes. Our findings contribute to research documenting widespread effects of the $9 / 11$ terrorist attack on stress-related symptoms and suggest that greater attention must be placed on the needs of our youngest citizens and their caregivers.
\end{abstract}

$\mathbf{T}$ he year 2013 marked the 12th anniversary of the largest attack on civilians in the United States. On September 11, 2001, terrorists hijacked four passenger planes and crashed them into the World Trade Center towers, the Pentagon, and a field in Pennsylvania, killing more than 3,000 people. Threats of terrorism and risks to national security persisted with alerts issued by Attorney General John Ashcroft in October 2001, White House Director of Homeland Security Tom Ridge in December 2001, and the Federal Bureau of Investigation (FBI) in February 2002. Individuals across the nation and those overseas were living in a perpetual state of high terrorist threat. Eighty-four percent of Americans expected more attacks, and over half were afraid that they or their family members would be victims (Institute for Social Research, 2002). In the months that followed, $40 \%-50 \%$ of adults still feared for their safety, and $11 \%$ reported altered behavior such as avoidance of public gatherings (Eisenman et al., 2009).

Unlike other disasters, terrorism is not confined to a particular geographical area or time. The unpredictable, indefinite threat of terrorism can contribute to a continual state of stress and anxiety (Fremont, 2004). Attacks occur without warning, and the threat of terrorism is enduring, lacking a clear endpoint

Correspondence concerning this article should be addressed to Anne Conway, Columbia University, Social Work, 1255 Amsterdam St., Room 710, New York, NY 10007. Electronic mail may be sent to ac3292@columbia.edu. when victims realize that the worst is over. The goal of terrorism is to cause visible disaster and create an atmosphere of fear, intimidation, and continued threat of violence, destroying a sense of security and safety within the targeted population. This infliction and persistence of widespread fear, intimidation, mass anxiety, and panic renders terrorism a form of disaster associated with effects on a widespread level with consequences for a majority of the population, even those not directly affected (Institute of Medicine, 2002).

The attacks of September 11 and continued threat of terrorism were intentionally directed at all Americans both within the United States and abroad (Schuster et al., 2001). Consistent with the stress paradigm linking psychosocial stressors to health and mental health (Dohrenwend \& Dohrenwend, 1974; Link \& Phelan, 1995; Richman, Cloninger, \& Rospenda, 2008) and extensive reviews on the widespread impact of disasters and international terrorism (Norris, Friedman, \& Watson, 2002), the 9/11 terrorist attack and ensuing threat of terrorism served as a significant macrolevel stressor that affected the health and mental health of the nation. Individuals throughout the United States and Canada, along with Americans living overseas, reported reduced emotional well-being and safety (Apolone, Mosconi, \& La Vecchia, 2002; Speckhard, 2003), 90\% experienced some symptoms of stress, and almost $50 \%$ experienced substantial stress reactions (Schuster et al., 2001). Short-term psychological distress was also found to be associated with increased rates of adverse cardiovascular reports (arrhythmias; 
Lambert, Baron, McPherson, \& Lee, 2002; Shedd et al., 2004), and acute stress reactions to $9 / 11$ were associated with a $53 \%$ increase in cardiovascular ailments in a national study 3 years later (Holman et al., 2008).

Mental health was also affected. For example, 52\% felt depressed, $62 \%$ had trouble sleeping, $66 \%$ had trouble concentrating, and $50 \%$ felt that their safety and security had been shaken (Institute for Social Research, 2001). Even 600 miles away from the site of the attacks in Ann Arbor, Michigan, there was a significant increase in psychiatric disorders and a $49 \%$ increase in suicide attempts after $9 / 11$ compared with before 9/11, with effects remaining for 2 years (Starkman, 2006). In the month after the attack, depressive symptoms rose nationally (Knudsen, Roman, Johnson, \& Ducharme, 2005), and symptoms of anxiety, posttraumatic stress disorder (PTSD), and alcohol consumption increased in the Midwest in the months after 9/11, with effects remaining 4 years later (Richman et al., 2008). Women were particularly vulnerable, with those experiencing chronic work stress demonstrating increased psychological distress, anxiety, and alcohol use after 9/11 (Richman, Wislar, Flaherty, Fendrich, \& Rospenda, 2010). In sum, a significant body of literature has demonstrated widespread stress, health, and mental health effects of the attack of $9 / 11$ and the continued threat of terrorism.

One group that was particularly affected was mothers. Single mothers living with children were more likely to feel threatened, and parents were more shaken by the attacks and remained disturbed for at least 1 year compared with other adults (Institute for Social Research, 2002; Phillips, Prince, \& Schiebelhut, 2004). Likewise, the stress reactions of mothers in Seattle, Washington, were associated with higher levels of school children's posttraumatic stress symptoms, whereas maternal acceptance (vs. rejection) of children predicted lower levels of posttraumatic stress symptoms (Wilson, Lengua, Meltzoff, \& Smith, 2010). Consistent with the ecological-transactional model of community violence (Lynch \& Cicchetti, 1993) and consistent relations between parent and child trauma-related symptoms (Scheeringa \& Zeanah, 2001), the 9/11 attack and threat of terrorism were associated with parenting stress, which, in turn, was associated with children's distress.

Although less attention has been given to effects on children than adults, evidence indicates that, nationwide, $35 \%$ of children between the ages of 5 and 18 had at least one of five trauma-related stress symptoms (Schuster et al., 2001) with $50 \%$ maintaining symptoms for 1-2 months (Stein et al., 2004). Retrospective accounts indicate that over $70 \%$ of school-age children within 100 miles of the attacks reported experiencing at least one symptom of PTSD such as intrusive thoughts, poor concentration, hyperarousal, and sleep problems (Aber, Hoven, \& Kotler, 2003; Phillips et al., 2004). Twelve percent had probable separation anxiety, and $28 \%$ had evidence of anxiety or depressive disorders (Hoven et al., 2004, 2005). Supporting findings of clinically significant sleep problems in adults under high terrorist threat (Palmieri, Chipman, Canetti, Johnson, \& Hobfoll, 2010), increased difficulties with sleep were also evident after 9/11, with youth significantly more likely to report being worried at bedtime than before $9 / 11$, and preschoolers exposed to high-intensity World Trade Center attacks were at increased risk of sleep problems (Chemtob, Nomura, \& Abra- movitz, 2008; Mijanovich \& Weitzman, 2010; Nomura \& Chemtob, 2009).

One important gap in the literature, however, is that, despite the widespread attention on older children and adults, almost no research has explored the effects of $9 / 11$ on toddlers and their parents using longitudinal or quasiexperimental designs. Numerous clinical reports and retrospective accounts indicate that children 5 years old and younger were affected by the tragedy, based on parents' retrospective interviews suggesting high levels of stress symptoms in children 5 years old and younger (DeVoe, Bannon, \& Klein, 2006). Indeed, parent interviews 9-12 months postdisaster by DeVoe et al. (2006) revealed that children in New York City had new fears $(52 \%)$, more aggression $(23 \%)$, sleep problems (43\%), clinging behavior $(44 \%)$, and upset during parental separation $(33 \%)$. Likewise, preschoolers exposed to high-intensity World Trade Center attacks demonstrated (a) increased risk of sleep problems, anxiety, or depression; (b) clinically significant emotionally reactive, anxious, or depressed, and sleep problems if they also had been exposed to prior trauma; and (c) emotionally reactive and aggressive behavior problems if their mothers evidenced depression or PTSD (Chemtob et al., 2008, 2010; Nomura \& Chemtob, 2009). However, given that these studies were based exclusively on retrospective reports of their children's behavior following the attack of $9 / 11$, the extent to which these symptoms reflect changes from preexisting levels following the attack cannot be determined. It is possible that these children may have demonstrated emotional distress and sleep difficulties even before the attack occurred. Therefore, without information on preexisting levels of symptoms, the extent to which the attack of $9 / 11$ altered symptoms in toddlers and their mothers is not clear.

Research on the impact of war, terrorism, and various types of disasters is often limited methodologically because of an inability to use standard experimental designs (North \& Pfefferbaum, 2002). Because of the unpredictable nature of these traumatic events, researchers rarely have preexisting symptom levels of their participants. In addition, the frequent use of retrospective reports compared with prospective data is also problematic. This study seeks to overcome these limitations using a quasiexperimental design to examine changes in health, mental health, and symptoms of emotional distress in mothers and their toddlers before and after the attacks of September 11. To date, no studies have compared preexisting and postattack symptoms in toddlers following the attack and, given relations between sleep difficulties and both terrorist threat and parenting stress and health (Lavie, 2001; Melzer \& Mindell, 2007; Palmieri et al., 2010), these may include difficulty sleeping and emotional distress such as crying (Scheeringa \& Gaensbauer, 2000; Scheeringa, Zeanah, Drell, \& Larrieu, 1995).

\section{Research Issues}

Our study adds to the growing literature on the effects of disaster and terrorism on children and mothers' functioning in several ways. Whereas much of the existing literature has examined the effects of disaster and terrorism on older children and adults, this work examined the effects of terrorism on toddlers and their mothers. We assessed these effects on several stress- 
related symptoms that have been found to be associated with disaster. These include changes in crying, sleeping, anxiety, depression, and parenting stress.

This research is also unique for its inclusion of baseline levels of symptoms, which is very rare in studies of disaster and terrorism. Because disastrous and terrorist events are often unpredictable, most studies of stress-related symptoms are based on retrospective reports. Consequently, few studies are able to account and control for preexisting symptom levels and rule out the possibility that symptom levels existed prior to the event. Our natural, quasiexperimental design provided a unique opportunity to examine whether stress-related symptom levels in 33-month-old toddlers and their mothers increased after the 9/11 attack and ensuing terrorist threat, compared with their levels at 15 months.

As we were conducting our 33-month assessments of our longitudinal study (McDonough, 1994), the attacks of $9 / 11$ occurred. This historical event created a naturalistic design in which we had a group of toddlers and their mothers who had their 33-month assessment before the attacks and another group who had their 33-month assessment as the study continued after the attacks. All assessments after 9/11 were conducted within 3 months following the attacks and during the period of highest terrorist threat and four nationwide terror alerts. Using this quasiexperimental design, we compared 33-month-old toddlers and their mothers who were assessed before the attacks occurred with those assessed after the attacks occurred. Capitalizing upon existing baseline data, we controlled for levels of stress-related symptoms that toddlers and their mothers had at a prior 15-month assessment.

Based on the stress paradigm linking psychosocial stressors to health and mental health (Dohrenwend \& Dohrenwend, 1974; Link \& Phelan, 1995), as applied to macrolevel stress of the 9/11 terrorist attack and ensuing threats (Richman et al., 2008), we hypothesized that, controlling for 15-month levels, mothers and toddlers who had their 33-month assessment after 9/11 would have higher levels of stress-related symptoms compared with those who had their follow-up assessment before 9/11. Our main questions were as follows: Compared with their levels at 15 months, do 33-month-old toddlers who were assessed after the 9/11 attack evidence more crying and less sleeping than those who were assessed before the 9/11 attack? Compared with their levels at 15 months, do mothers of 33month-old toddlers who were assessed after the 9/11 attack evidence more anxiety, depression, health problems, and parenting stress than those who were assessed before the 9/11 attack?

\section{Method}

\section{Participants}

An ongoing longitudinal study provided us with the unique opportunity to examine the effects of the $9 / 11$ attack with existing baseline data. Specifically, data are from a longitudinal study of the development of self-regulation in a sample of children during the first 3 years of life and their families, living in the Midwest, several hundred miles from the events of September 11. The Michigan Family Study (McDonough, 1994), begun in the late 1990s, collected data on the participants' history of mental health symptomatology, parenting, and family and environmental risks when the children were 7,15 , and 33 months of age. The entire sample had completed the 15-month assessment, and most families had completed the 33-month assessments before September 11, 2001. The 33-month sample includes dyads that were assessed before or after the attacks of 9/11. A smaller group that completed the assessments after $9 / 11$ permitted us to examine the effects of the terrorist act and threat of terrorism. Indeed, the existence of before-attack (BA) and after-attack (AA) subgroups and preexisting levels of all study variables allowed for a rare quasiexperimental test of the impact of terrorism on mental health symptoms in families with young children.

Two hundred and fifty-two infants (54\% females) were enrolled at 7 months of age (Table 1). Of these, 221 children and mothers were assessed at 15 months (six relocated, 25 declined), and 191 children were assessed at 33 months (11 relocated, 19 declined) -169 before and 22 after $9 / 11$. Of the original sample, $55 \%$ of the infants were female, and $45 \%$ were male. Seventy-five percent were Euro-Americans, 13\% African American, 1\% Latino, 7\% biracial, and 3.6\% were classified as "Other." Average age for mothers was 29 years (range 16-43). Ninety-six percent of mothers had at least a high school degree or GED; $92 \%$ were married or living with a partner. The median annual family income at both ages was between $\$ 50,000$ and $\$ 55,000$. Multivariate analysis of variance (MANOVA) comparing maternal age, years of education, and family income between the participants and nonparticipants and chi-square analyses on remaining categorical variables were not significant, suggesting attrition was random. Likewise, no significant differences were found on 15-month (Time 1) measures of toddler and maternal stress-related symptoms. Demographic characteristics were also compared for the BA and AA groups at 33 months, and both groups were equivalent on all demographic and dependent variables at 15 months.

\section{Procedure}

At 15 and 33 months of age, mothers were visited in their homes by trained interviewers who collected demographic

Table 1. Sample Demographics $(\mathrm{n}=194)$

\begin{tabular}{ll}
\hline Variable & \multicolumn{1}{c}{ Statistic } \\
\hline Average maternal age (years) & 31 (range 17-44) \\
Average paternal age (years) & 32 (range 20-54) \\
Median income & $\$ 50,000-\$ 55,000$ \\
Percentages & \\
Maternal education & \\
High school/GED or above & $90 \%$ \\
Paternal education & \\
High school/GED or above & $100 \%$ \\
Maternal marital status & \\
Married/living with partner & $91 \%$ \\
Child sex (male) & $43 \%$ \\
No siblings/l-2 siblings & $55 \%, 45 \%$ \\
Child race & \\
African American & $8.50 \%$ \\
Asian American & $3.50 \%$ \\
European American & $80 \%$ \\
Latino & $1 \%$ \\
Biracial & $7 \%$ \\
\hline
\end{tabular}


information during an interview. Following the interview, the mothers completed a packet of questionnaires. Mothers rated parenting stress and emotional distress or mental health. Toddler's crying and sleeping behavior was reported at 15 and 33 months.

\section{Measures-15 and 33 Months}

Maternal anxiety. Mothers reported their levels of anxiety using the 20-item Spielberg State Anxiety Scale (STAI; Spielberger, 1983). The degree to which a statement applied to the mother was rated with a 4-point scale from 1 (never) to 4 (always). Examples include "I feel anxious." Cronbach's alphas for the scale at 15 and 33 months were 0.92 and 0.91 , respectively.

Maternal depression symptomatology. Mothers reported their levels of depressive symptomatology using the Center for Epidemiological Studies of Depression Scale (CES-D; Radloff, 1977). Items were rated on a 4-point Likert scale, 0 ( $<1$ day per week) to 3 (5-7 days per week). Examples include "felt depressed" and "talked less than usual." Total scores were summed and reflected the level of depressive symptomatology. Cronbach's alphas for the scale at 15 and 33 months were 0.89 and 0.91 , respectively.

Child crying. Mothers reported their perceptions of their child's crying patterns using the Cry Patterns Questionnaire (CPQ; St. James-Roberts \& Halil, 1991). Maternal estimates of morning, afternoon, evening, and night crying were obtained, and the 24-hr total was calculated.

Child sleep. Mothers reported their child's sleeping patterns using the Sleep Habits Questionnaire (Owens, Spirito, \& McGuinn, 2000; Seifer, Sameroff, Dickstein, \& Hayden, 1996). Children's 24-hr sleep total was calculated.

Parenting stress. Mothers reported their parenting stress using subscales from the Parenting Stress Inventory (PSI; Abidin, 1986). Twenty-six items were included that measure parenting stress in the child domain (those characteristics of the child that make parenting difficult) and the parent domain (those characteristics or roles in the parenting relationship that can make parenting difficult). Specifically, we included three subscales: Acceptability, Competence and Health Problems. Most items were rated on a 5-point Likert scale, 1 (strongly agree) to 5 (strongly disagree), and four were rated on a 4-point scale. Cronbach's standardized alphas for the subscales ranged from 0.72 to 0.78 .

\section{Results}

\section{Analytic Strategy}

To examine group differences across time in symptomatology, $2 \times 2$ (Group $\times$ Time) multivariate repeated measures analyses of variance were conducted using dependent variables grouped by (a) maternal and child emotional stress symptoms and (b) parenting stress and health. Because of the use of an unbalanced design, we used general linear models for all analyses and report Pillai's Trace statistics. Next, $2 \times 2$ (Group $\times$ Time) univariate analyses of variance and post hoc comparisons were conducted for each of the dependent variables. Specifically, the behaviors at 15 months were compared with behaviors at 33 months. Then, comparisons were made between the BA and AA subgroups. To correct for sphericity common in repeated measures analysis, the Greenhouse-Geisser correction was used (Greenhouse \& Geisser, 1959). The Bonferroni correction was used to test all post hoc comparisons.

\section{Emotional Stress Symptoms}

Results of the Group $\times$ Time multivariate repeated measures analysis of variance using the four emotional stress-related dependent variables yielded a nonsignificant main effect for group, but a significant effects for time, Pillai's Trace, $F(4$, $171)=14.09, p<.01$, and a Group $\times$ Time interaction, Pillia's Trace, $F(4,171)=3.25, p<.01$.

Follow-up univariate repeated-measures analysis of variance was conducted for each dependent variable (see Table 2). No main effects of group were revealed. For crying, significant effects were noted for time, $F(1,174)=9.79, p<.01$, and a Group $\times$ Time interaction, $F(1,174)=5.99, p<.01$. For sleep, significant effects were revealed for time, $F(1,174)=46.87$, $p<.01$, but this was subsumed under a Group $\times$ Time interaction, $F(1,174)=5.74, p<.01$. There was also a marginal Group $\times$ Time interaction for maternal anxiety, $F(1$, $174)=2.65, p=.10$. The post hoc tests revealed differences in the expected direction. Compared with the BA group, the AA group of 33-month-old toddlers engaged in significantly more crying $(p<.01)$ and less sleeping $(p<.01)$ at 33 months than they did at 15 months (see Figures 1 and 2). Moreover, the mothers in the AA group reported marginally more anxiety at 33 months than the BA group $(p=.10)$.

\section{Parenting Stress and Health}

Results of the Group $\times$ Time multivariate repeated measures analysis of variance using the three parenting stress dependent variables yielded a nonsignificant main effect for group, but significant effects for time, Pillai's Trace $F(3,185)=3.61, p<.01$, and marginally significant Group $\times$ Time interaction, Pillai's Trace $F(3,185)=2.44, p<.06$.

Follow-up univariate repeated-measures analysis of variance was conducted for each dependent variable (see Table 3). No main effects of group were noted. However, for parenting competence stress, significant main effects were noted for time, $F(1,187)=5.56, p<.01$, with more parenting competence stress at 33 versus 15 months (Bonferroni, $p<.01$ ). For difficulties with acceptance of child, there was a significant main effects for time, $F(1,187)=8.88, p<.01$, with more difficulties at 33 versus 15 months (Bonferroni, $p<.01$ ), but this was subsumed under a significant Group $\times$ Time interaction, $F(1$, $187)=3.83, p<.05$. Likewise, for health difficulties, there were significant Group $\times$ Time interactions, $F(1,187)=5.16$, $p<.05$. Follow-up post hoc analyses using Bonferroni comparisons revealed that compared with BA mothers, AA 
Table 2. Mean Levels of Maternal and Toddler Emotional Stress Symptoms

\begin{tabular}{|c|c|c|c|c|c|}
\hline Variable & \multicolumn{2}{|c|}{ Pre-9/11 } & \multicolumn{2}{|c|}{ Post-9/11 } & $F$ statistic \\
\hline Maternal anxiety & $33.36(9.58)^{\mathrm{a}}$ & $33.96(8.47)^{\mathrm{a}}$ & $33.25(9.69)^{\mathrm{b}}$ & $36.62(9.57)^{\mathrm{b}}$ & 2.64 \\
\hline Toddler 24 -hr crying & $53.30(58.83)^{\mathrm{a}}$ & $60.36(78.74)^{\mathrm{a}}$ & $42.68(58.02)^{\mathrm{b}}$ & $102.68(81.30)^{\mathrm{b}}$ & $6.10^{* *}$ \\
\hline Toddler 24-hr sleeping & $769.05(104.70)^{\mathrm{a}}$ & $710.34(69.15)^{\mathrm{a}}$ & $804.37(78.39)^{\mathrm{b}}$ & $682.5(71.41)^{\mathrm{b}}$ & $5.74 * *$ \\
\hline
\end{tabular}

Note. Numbers in parenthesis are standard deviations. Means in the same row that share superscripts differ at $p<.05$ in Bonferroni comparisons. Listwise deletion resulted in missing data and sample sizes of 160 and 16. $* p<.05 . * * p<.01$.

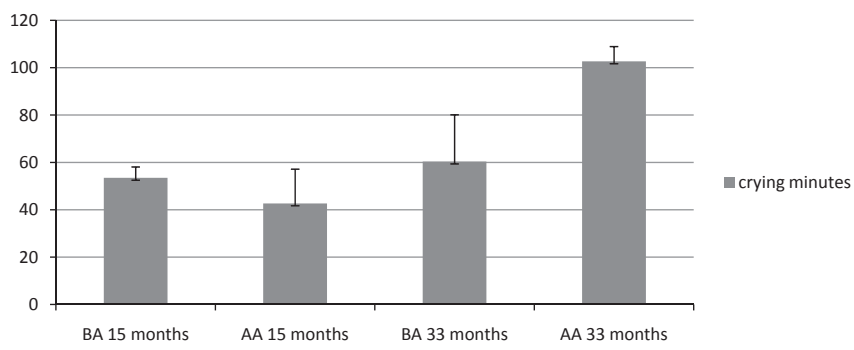

Figure 1. Total 24 -hr toddler crying by $9 / 11$ group and time (means and standard errors). $\mathrm{BA}=$ Before attack group; $\mathrm{AA}=$ After attack group.

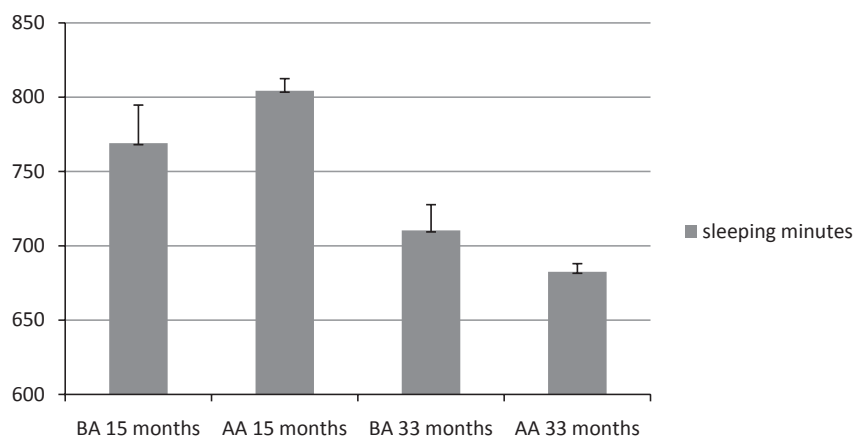

Figure 2. Total 24-hr toddler sleeping by $9 / 11$ group and time (means and standard errors). $\mathrm{BA}=$ Before attack group; $\mathrm{AA}=$ After attack group.

mothers reported significantly more health difficulties and greater difficulties accepting their child than they did at 15 months (see Figures 3 and 4).

\section{Discussion}

Based on the macrolevel stress paradigm (Dohrenwend \& Dohrenwend, 1974; Link \& Phelan, 1995; Richman et al., 2008), we predicted that mothers and toddlers exposed to the 9/11 terrorist attack and the ensuing national threats of terrorism 3 months following the attack would demonstrate changes in stress-related symptoms compared with before the attack. Data from two assessment waves supported our hypothesis and documented increases in the stress-related symptoms of AA mothers and toddlers compared with BA mothers and toddlers.

To date, little research has examined the impact of 9/11 and the threat of terrorist attacks on toddlers. Perhaps, widespread beliefs exist that toddlers are too young to understand and consequently be impacted by terrorism and terrorist threat. However, our data support numerous observations by clinicians and demonstrate that children as young as 2 years of age are affected by tragedies such as that of $9 / 11$ and ongoing terrorist threat (Gurwitch, Sitterle, Young, \& Pfefferbaum, 2002).

Consistent with the growing body of research demonstrating both short- and long-term effects of the 9/11 terrorist attack and terrorist threat throughout the nation and abroad, our data suggest that toddlers do not need to directly witness a terrorist attack to experience its adverse effects. As the results of this study reveal, toddlers and their mothers far away from the site of the attacks in the Midwest demonstrated significant changes following the tragic events of September 11 and the ensuing period of terrorism threat. These findings support clinical reports that children across the nation were experiencing symptoms of distress and contribute to the large body of evidence for nationwide effects of terrorism and terrorist threat. Given that both terrorist attacks and terrorist threats have been demonstrated to elicit stress-related symptoms and difficulties

Table 3. Mean Levels of Parenting Stress and Health Symptoms

\begin{tabular}{|c|c|c|c|c|c|}
\hline Variable & \multicolumn{2}{|c|}{ Pre-9/11 } & \multicolumn{2}{|c|}{ Post-9/11 } & $F$ statistic \\
\hline Parenting competence (stress) & $5.55(1.97)$ & $5.72(1.88)$ & $5.30(1.68)$ & $6.20(2.21)$ & 2.53 \\
\hline Acceptability of child (difficulties) & $10.30(3.07)$ & $10.75(3.03)$ & $9.85(2.90)^{\mathrm{a}}$ & $12.05(6.21)^{\mathrm{a}}$ & $3.83^{*}$ \\
\hline
\end{tabular}

Note. Numbers in parenthesis are standard deviations. Means in the same row that share superscripts differ at $p<.05$ in Bonferroni comparisons. ${ }^{*} p<.05$. 


\section{Maternal Health Difficulties}

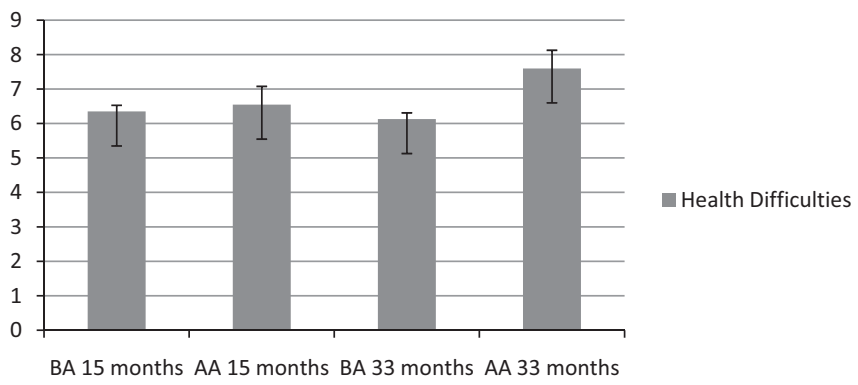

Figure 3. Maternal health difficulties by $9 / 11$ group and time (means and standard errors). $\mathrm{BA}=$ Before attack group; $\mathrm{AA}=$ After attack group.

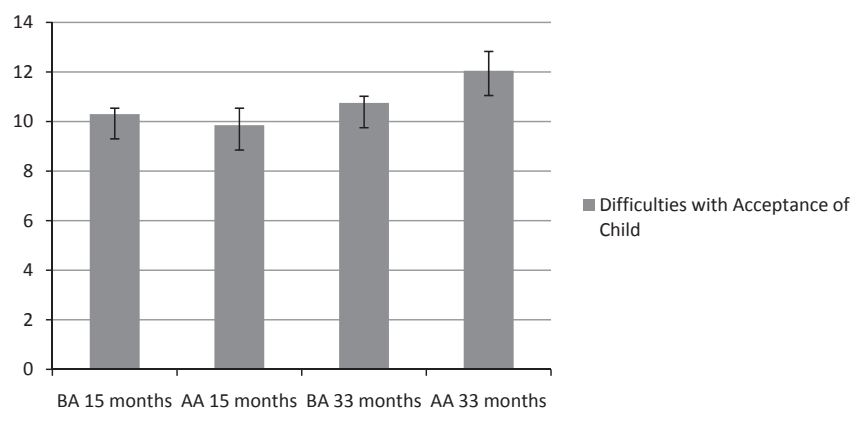

Figure 4. Difficulties with acceptance of child by $9 / 11$ group and time (means and standard errors). $\mathrm{BA}=$ Before attack group; $\mathrm{AA}=$ After attack group.

in adults across the nation, the changes documented in this study may have developed because of the ensuing terrorist threat and instilled fear, the terrorist attack and distant trauma, or a combination of both macrolevel stressors.

Distant trauma refers to "the reaction (memory, thinking, symptoms) to a disastrous event, experienced at the time of the event, but from a remote and realistically safe distance" (Terr et al., 1999, p. 1543). While the impact of disastrous events can be greatest on those who experienced them directly, there is evidence that even individuals who do not experience disasters directly are affected by them (e.g., Pfefferbaum et al., 2000; Terr et al., 1999). Children indirectly exposed to a catastrophic event can be expected to demonstrate stress-related symptoms of posttraumatic stress and anxiety even if they are distant from the site of the event (Lengua, Long, Smith, \& Meltzoff, 2005). When considering disasters of political violence such as terrorist and ongoing terrorist threat, the boundaries between direct and distant trauma overlap slightly, as the mothers and children in this study were not targets of the specific attack on 9/11 on the East Coast but, like all American citizens, were targets of the ensuing national threatened attacks. Therefore, the overlapping and unique effects and needs of those living under the macrostressor of a terrorist attack and the macrostressor of ensuing terrorist attacks must be equally addressed in research and practice. Indeed, the infliction of fear through random and unpredictable acts of murder can extend to individuals across a nation (Gurwitch et al., 2002; Pfefferbaum, North, et al., 2003). Our findings demonstrate that it not only affects adults and adolescents (Costello, Erkanli, Keeler, \& Angold, 2004), but can also impact toddlers.

Our findings also indicate that mothers of young children were also affected by the attack. Not only were marginal changes in anxiety observed (which may have been significant with a larger sample size and greater statistical power), but the event also appeared to reduce mothers' health and acceptance of their child. In contrast to other studies (Knudsen et al., 2005), increases in depressive symptoms were not observed. In sum, results from this study demonstrate that the attack of 9/11 resulted in increased health difficulties in mothers, lower acceptance of their child, and increased levels of crying and decreased levels of sleep in their toddlers. This combination of effects underscores the importance of examining the impact of national disasters and terrorism and terrorist attacks, specifically.

Strengths of the current study are the use of a quasiexperimental, longitudinal design consisting of baseline levels of stress-related symptomatology and the use of a control group, which is rare in studies of large-scale terrorism and terrorist threat. Likewise, all assessments following 9/11 were conducted 3 months following the terrorist attack, within the period of highest terrorist threat and four nationwide terror alerts.

Nevertheless, a number of limitations warrant caution in interpretation of the results. The first pertains to omitted variable bias. It is possible that the changes in symptom levels following 9/11 may be because of other unmeasured variables such as perceptions of possible risks to financial or job security. Second, caution must be taken in inferring causality. Although this study addressed limitations in prior research by capitalizing on a unique opportunity to use a prospective, longitudinal, quasiexperimental design to control for baseline symptoms levels, the quasiexperimental nature of the design precludes our ability to make definitive causal statements.

Likewise, the use of parent report measures of child outcomes, which is necessary at this age group, may reflect rater bias and may be associated with inflation of child symptoms. Although a number of studies have reported that, in comparison with children's self-reports, parents underestimate the impact and severity of trauma on children (Scheeringa \& Zeanah, 2008), it is possible that, rather than inflating children's ratings of symptomatology, parents in this study may have underestimated the impact and severity of terrorism and terrorist threat on their toddlers. Nevertheless, inclusion of observational, physiological, and fine-grained assessments of total 24-hr toddler sleeping and crying behavior would decrease the possibility of rater bias.

Likewise, the study is limited by the small number of participants that were assessed after 9/11. The unequal sample size and, specifically, the small size of one of our comparison groups is a limitation of our study. Following Peterson's (2007) methodological and statistical guidelines and recommendations for best practices using small samples in quantitative research, we situate our rationale for the use of our small sample within the paucity of literature and knowledge pertaining to the effects of $9 / 11$, other terrorist attacks, and ongoing terrorist threat on mothers and toddlers (while controlling for preexisting symp- 
tom levels). No studies to date have reported on the effects of 9/11 on toddlers using baseline versus retrospective data and, coupled with the rare opportunity to provide findings on the effects of $9 / 11$ on young toddler and their mothers, support our rationale for using the available comparison group, even though it is small.

Given the tragic and unpredictable nature of disaster and international terrorism, one does not know when such a horrible historical event will occur and, in the case of terrorism, this often leads to a prolonged period of heightened threat and vigilance throughout the nation and abroad. Consequently, research on disaster and "the ethical and practical dilemmas ... represent rare data obtained by methods that may not meet typical standards of scientific rigor and the value is generally based upon the judgment of potential value and unique contribution ... in the context of current knowledge" (Masten \& Osofsky, 2010, p. 1029). Yet, the findings from our study are important, given that no studies have been published documenting the effects of $9 / 11$ and international terrorism on toddlers and their families that control for preexisting, baseline, individual differences. To date, we know very little about the effects on toddlers and their parents, given the challenges inherent in disaster research. The few reported findings that exist are based on retrospective reports, and our study provides a contribution to expand our current knowledge about the effects of terrorism and terrorist threat on toddlers and their mothers geographically distant from the site of attack. Our study provides a unique opportunity to address this gap and further our understanding of these effects on young children. Nevertheless, the results of this study should be interpreted within the context of a small comparison group and as the first study to examine these effects in young children while controlling for preexisting levels.

Many studies examining geographically distant sites involve nationally representative samples, and others reflect samples limited to regions such as the Midwest (e.g., Chicago, Michigan, etc.). Comparable to our study, Starkman (2006) assessed individuals residing within Ann Arbor, Michigan, which is over 600 miles from the site of the attack, and reported significantly higher levels of suicide attempts following 9/11 compared with before 9/11. Likewise, our study demonstrated significant increases in stress-related symptoms in mothers and their toddlers who were also in Michigan, geographically distant from the site of the attacks. Although our findings contribute to existing work in this area, it is also important to recognize that our findings may not generalize to individuals across the United States.

Finally, given that this analysis was based on an ongoing longitudinal study developed prior to the tragedy, we did not have measures of the $9 / 11$ attack in terms of exposure to the attack, media coverage, relations to victims, perceived threat, and prior trauma, which have all been documented to significantly increase stress-related responses to validate proximal exposure (Hoven, Duarte, \& Mandell, 2003; Pfefferbaum, et al., 2003a,b,c). Nevertheless, without measures of those additive effects and validation of proximal exposure, we demonstrated significant changes from baseline symptomatology within the first 2 months following the terrorist attack. Studies assessing the additive effects of direct exposure and their asso- ciations with symptom changes are urgently needed to inform the postdisaster environment and public health agenda.

Nevertheless, the goal of terrorism is to inflict widespread fear among members of an identified group, and, consequently, the effects of terrorism may have no geographical bounds and extend beyond proximal locations. Indeed, a growing body of research has demonstrated that terrorism and ongoing terrorist threat have a significant impact on individuals geographically distant and hundreds of miles away from the site of an attack. Widespread stress-related changes have also been observed across populations in London, England, Israel, and the United States with minimal exposure (Marshall et al., 2007). Therefore, direct exposure and proximity to a terrorist attack may not be the only avenue for the development of stress-related symptoms compared with other disasters, particularly given the widespread possibility of unpredictable attacks. Therefore, unlike disasters with geographically specific boundaries, research on the effects of terrorism and ongoing terrorist threat should be broadened to consider the effects on individuals with low levels of proximity and exposure to a terrorist attack, yet who experience ongoing terrorist threats, and the processes through which these may occur. This may enhance our understanding of unique and specific effects of terrorism compared with other disasters and may contribute to a greater appreciation of the potentially widespread effects and needs following national and international effects of terrorism, particularly among vulnerable groups, and which may currently be underappreciated.

In sum, the findings from the study suggest that children as young as 33 months of age and their mothers experienced significant stress-related changes following the terrorist attacks and during heighted terrorist threat following 9/11. Furthermore, these effects were observed for mothers and toddlers who were several hundred miles from the site of the attacks. Therefore, these findings contribute to the growing body of literature on the unique and widespread population level effects of terrorist disasters. We can no longer assume that only those directly exposed to terrorism are adversely affected (Gurwitch et al., 2002), and the unique, widespread effects of terrorist threat suggest the importance of coordinated, widespread national attention and efforts. Researchers and clinicians should consider the reactions of toddlers and their parents in daily settings such as daycare centers, hospitals, and community shelters. Early detection of adverse acute reactions and timely interventions are critical to facilitating recovery in the postattack, ongoing terrorist threat environment, particularly as it may reduce risk of parenting stress, harsh parenting, and child abuse, heightened under conditions of pediatric excessive crying and sleep difficulties (Reijneveld, van der Wal, Brugman, Hira Sing, \& Verloove-Vanhorick, 2004).

\section{Clinical Implications}

These findings suggest that greater attention must be placed on the effects of terrorist attacks, threat, and other forms of disasters on our youngest citizens across the nation. These effects provide support for the impact of macrolevel stressors such as terrorism and threat on population level health and mental health changes. Likewise, consistent with prior research, the effects of stress on children may have occurred indirectly 
through transactional processes involving parental reactions. Therefore, assessments of the potentially unique impact of terrorist attack and threat must be conducted on a widespread level and for toddlers and caregivers. Numerous studies have documented that parental reactions to disaster and accompanying disaster-related challenges are significant predictors of children's distress and should be targeted for intervention (Green et al., 1991). Thorough assessment of the functioning of the parent and the child should be considered (Zeanah, Larrieu, Heller, \& Valliere, 2000), and interaction guidance and multisystemic approaches may prove useful in addressing the parenting relationship (McDonough, 2004).

Keywords: toddlers; mothers of toddlers; terrorism; terrorist threat; terrorist attack; posttraumatic stress; child trauma symptoms; proximity to terrorist attack; September 11

\section{References}

Aber, J. L., Hoven, C., \& Kotler, J. (2003, April). The New York City Board of Education's assessment of the impact of September 11th on New York City public school students. Paper presented at the biennial meeting of the Society for Research in Child Development, Tampa, FL.

Abidin, R. R. (1986). Parenting Stress Index: Manual. Odessa, FL: Psychological Assessment Resources.

Apolone, G., Mosconi, P., \& La Vecchia, C. (2002). Post-traumatic stress disorder. New England Journal of Medicine, 346, 1495-1496.

Chemtob, C. M., Nomura, Y., \& Abramovitz, R. A. (2008). Impact of conjoined exposure to the World Trade Center attacks and to other traumatic events on the behavioral problems of preschool children. Archives of Pediatrics and Adolescent Medicine, 162, 126-133.

Chemtob, C. M., Nomura, Y., Rajendran, K., Yehuda, R., Schwartz, D., \& Abramovitz, R. (2010). Impact of maternal posttraumatic stress disorder on depression following exposure to the September 11 attacks on preschool children's behavior. Child Development, 81, 1129-1141.

Costello, E. J., Erkanli, A., Keeler, G., \& Angold, A. (2004). Distant trauma: A prospective study of the effects of $9 / 11$ on rural youth. Applied Developmental Science, 8, 211-220.

DeVoe, E. R., Bannon, W. M., \& Klein, T. P. (2006). Post-9/11 helpseeking by New York City parents on behalf of highly exposed young children. American Journal of Orthopsychiatry, 76, 167-175.

Dohrenwend, B. S., \& Dohrenwend, B. P. (1974). Overview and prospects for research on stressful life events. In B. S. Dohrenwend \& B. P. Dohrenwend (Eds.), Stressful life events: Their nature and events (pp. 313-331). New York, NY: Wiley.

Eisenman, D. P., Glik, D., Ong, M., Zhou, Q., Tseng, C.-H., Long, A., $\&$ Asch, S. (2009). Terrorism-related fear and avoidance behavior in a multiethnic urban population. American Journal of Public Health, 99, 168-174.

Fremont, W. P. (2004). Childhood reactions to terrorism-induced trauma: A review of the past 10 years. Journal of the American Academy of Child and Adolescent Psychiatry, 43, 381-392.

Green, B., Korol, M., Vary, M., Leonard, A., Gleser, G., \& SmitsonCohen, S. (1991). Children and disaster: Age, gender, and parental effects on PTSD symptoms. Journal of the American Academy of Child and Adolescent Psychiatry, 30, 945-951.

Greenhouse, S. W., \& Geisser, S. (1959). On methods in the analysis of profile data. Psychometrika, 24, 95-112.

Gurwitch, R. H., Sitterle, K. A., Young, B. H., \& Pfefferbaum, B. (2002). The aftermath of terrorism. In A. M. La Greca, W. K. Silverman, E. M. Vernberg, \& M. C. Roberts (Eds.), Helping children cope with disasters and terrorism (pp. 327-357). Washington, DC: American Psychological Association.

Holman, E. A., Silver, R. C., Poulin, M., Andersen, J., Gil-Rivas, V., \& McIntosh, D. N. (2008). Terrorism, acute stress, and cardiovascular health: A 3-year national study following the September 11th attacks. Archives of General Psychiatry, 65, 73-80.

Hoven, C. W., Duarte, C. S., Lucas, C. P., Wu, P., Mandell, D. J., Goodwin, R. D., \& Susser, E. (2005). Psychopathology among New York City public school children 6 months after September 11th. Archives of General Psychiatry, 62, 545-552.

Hoven, C. W., Duarte, C. S., \& Mandell, D. J. (2003). Children's mental health after disasters: The impact of the World Trade Center attack. Current Psychiatry Reports, 5, 101-107.

Hoven, C. W., Duarte, C. S., Wu, P., Erickson, E. A., Musa, G. J., \& Mandell, D. J. (2004). Exposure to trauma and separation in children after the WTC attack. Applied Developmental Science, 8, 172-183.

Institute for Social Research. (2001). How America responds: Part 2. Retrieved from University of Michigan News Information Service. http://www.umich.edu/ newinfo/Releases/2001/Oct01/r100901b.html

Institute for Social Research. (2002). Homeland insecurity. Social Science in the Public Interest, 1(2), 1-8.

Institute of Medicine. (2002). Preparing for terrorism: Tools for evaluating the Metropolitan Medical Response System Program, Institute of Medicine. Washington, DC: National Academy Press.

Knudsen, H. K., Roman, P. M., Johnson, J. A., \& Ducharme, L. J. (2005). A changed America? The effects of September 11th on depressive symptoms and alcohol consumption. Journal of Health \& Social Behavior, 46, 260-273.

Lambert, R., Baron, S. J., McPherson, C. A., \& Lee, F. A. (2002). Heart rate variability during the week of September 11, 2001. Journal of the American Medical Association, 288, 575.

Lavie, P. (2001). Sleep disturbances in the wake of traumatic events. New England Journal of Medicine, 345, 1825-1832.

Lengua, L. J., Long, A. C., Smith, K. I., \& Meltzoff, A. N. (2005). Preattack symptomatology and temperament as predictors of children's responses to the September 11 terrorist attacks. Journal of Child Psychology and Psychiatry, 46, 631-645.

Link, B. G., \& Phelan, J. (1995). Social conditions as fundamental causes of diseases. Journal of Health and Social Behavior, 30, 80-94.

Lynch, M., \& Cicchetti, D. (1993). An ecological-transactional analysis of children and contexts: The longitudinal interplay among child maltreatment, community violence, and children's symptomatology. Development and Psychopathology, 10, 235-257.

Marshall, R. D., Bryant, R. A., Amsel, L., Suh, E. J., Cook, J. M., \& Neria, Y. (2007). The psychology of ongoing threat: Relative risk appraisal, the September 11 attacks, and terrorism-related fears. American Psychologist, 62, 304-316.

Masten, A. S., \& Osofsky, J. D. (2010). Disasters and their impact on child development: Introduction to the special section. Child Development, 81, 1029-1039.

McDonough, S. C. (1994). Preventing mental health problems in multirisk infants (National Institute of Mental Health RO1 Grant Proposal). Ann Arbor, MI: University of Michigan.

McDonough, S. C. (2004). Interaction guidance: Promoting and nurturing the caregiving relationship. In A. J. Sameroff, S. C. McDonough, \& K. L. Rosenblum (Eds.), Treating parent-infant relationship problems: Strategies for intervention (pp. 79-96). New York, NY: Guilford.

Melzer, L. J., \& Mindell, J. A. (2007). Relationship between child sleep disturbances and maternal sleep, mood, and parenting stress: A pilot study. Journal of Family Psychology, 21, 67-73.

Mijanovich, T., \& Weitzman, B. C. (2010). Disaster in context: The effects of $9 / 11$ on youth distant from the attacks. Community Mental Health Journal, 46, 601-611. 
Nomura, Y., \& Chemtob, C. M. (2009). Effect of maternal psychopathology on behavioral problems in preschool children exposed to terrorism. Archives of Pediatrics and Adolescent Medicine, 163, 531539.

Norris, F. H., Friedman, M. J., \& Watson, P. J. (2002). 60,000 disaster victims speak: Part II. Summary and implications for disaster mental health research. Psychiatry, 65, 240-260.

North, C., \& Pfefferbaum, B. (2002). Research on the mental health effects of terrorism. Journal of the American Medical Association, 288, 333-336.

Owens, J. A., Spirito, A., \& McGuinn, M. (2000). The Children's Sleep Habits Questionnaire (CSHQ): Psychometric properties of a survey instrument for school-aged children. Sleep, 23, 1-9.

Palmieri, P. A., Chipman, K. J., Canetti, D., Johnson, R. J., \& Hobfoll, S. E. (2010). Prevalence and correlates of sleep problems in adult Israeli Jews exposed to actual or threatened terrorist or rocket attacks. Journal of Clinical Sleep Medicine, 6, 557-564.

Peterson, N. A. (2007). Designing a rigorous small sample study. In J. Osbourne (Ed.), Best practices in quantitative methods (pp. 137-146). New York, NY: Sage.

Pfefferbaum, B., North, C. S., Doughty, D. E., Fullerton, C. S., Gurwitch, R. H., \& Kyula, J. (2003). Posttraumatic stress and functional impairment in Kenyan children following the 1998 American Embassy bombing. American Journal of Orthopsychiatry, 73, 133140.

Pfefferbaum, B., Pfefferbaum, R. L., Gurwitch, R. H., Nagumalli, S., Brandt, E. N., Robertson, M. J., \& Saste, V. S. (2003). Children's response to terrorism: A critical review of the literature. Current Psychiatry Reports, 5, 95-100.

Pfefferbaum, B., Seale, T. W., Brandt, E. N., Pfefferbaum, R. L., Doughty, D. E., \& Rainwater, S. M. (2003). Media exposure in children one hundred miles from a terrorist bombing. Annuals of Clinical Psychiatry, 15, 1-8.

Pfefferbaum, B., Seale, T. W., McDonald, N. B., Brandt, E. N., Rainwater, S. M., Maynard, B. T., \& Miller, P. D. (2000). Posttraumatic stress two years after the Oklahoma City bombing in youths geographically distant from the explosion. Psychiatry, 63, 358-370.

Phillips, D., Prince, S., \& Schiebelhut, L. (2004). Elementary school children's responses 3 months after the September 11 terrorist attacks: A study in Washington, DC. American Journal of Orthopsychiatry, 74, 509-528.

Radloff, L. S. (1977). The CES-D Scale: A self-report depression scale for research in the general population. Applied Psychological Measurement, 1, 385-401.

Reijneveld, S. A., van der Wal, M. F., Brugman, E., Hira Sing, R. A., \& Verloove-Vanhorick, S. P. (2004). Infant crying and abuse. Lancet, $364,1340-1342$.

Richman, J. A., Cloninger, L., \& Rospenda, K. M. (2008). Macrolevel stressors, terrorism, and mental health outcomes: Broadening the stress paradigm. American Journal of Public Health, 98, 323329.

Richman, J. A., Wislar, J. S., Flaherty, J. A., Fendrich, M., \& Rospenda, K. M. (2010). Effects on alcohol use and anxiety of the September 11, 2001, attacks and chronic work stressors: A longitudinal cohort study. American Journal of Public Health, 94, 2010-2015.
Scheeringa, M. S., \& Gaensbauer, T. J. (2000). Posttraumatic stress disorder. In C. H. Zeanah (Ed.), Handbook of infant mental health (2nd ed., pp. 369-381). New York, NY: Guilford.

Scheeringa, M. S., \& Zeanah, C. H. (2001). A relational perspective on PTSD in early childhood. Journal of Traumatic Stress, 14, 799-815.

Scheeringa, M. S., \& Zeanah, C. H. (2008). Reconsideration of harm's way: Onsets and comorbidity patterns of disorders in preschool children and their caregivers following hurricane Katrina. Journal of Clinical Child and Adolescent Psychology, 37, 508-518.

Scheeringa, M. S., Zeanah, C. H., Drell, M. J., \& Larrieu, J. A. (1995). Two approaches to the diagnosis of posttraumatic stress disorder in infancy and early childhood. Journal of the American Academy of Child and Adolescent Psychiatry, 34, 191-200.

Schuster, M. A., Stein, B. D., Jaycox, L. H., Collins, R. L., Marshal, G. N., Elliott, M. N., \& Berry, S. H. (2001). A national survey of stress reactions after the September 11, 2001, terrorist attacks. New England Journal of Medicine, 345, 1507-1512.

Seifer, R., Sameroff, A. J., Dickstein, S., \& Hayden, L. C. (1996). Parental psychopathology and sleep variation in children. Child and Adolescent Psychiatric Clinics of North America, 5, 715-727.

Shedd, O. L., Sears, S. F., Harvill, J. L., Arshad, A., Conti, J. B., Steinberg, J. S., \& Curtis, A. B. (2004). The World Trade Center attack: Increased frequency of defibrillator shocks for ventricular arrhythmias in patients living remotely from New York City. Journal of the American College of Cardiology, 44, 1265-1267.

Speckhard, A. (2003). Acute stress disorder in diplomats, military, and civilian Americans living abroad following the September 11 terrorist attacks on America. Professional Psychology: Research and Practice, 34, 151-158.

Spielberger, C. D. (1983). Manual for the State-Trait Anxiety Inventory. Palo Alto, CA: Consulting Psychologists Press.

St. James-Roberts, I., \& Halil, T. (1991). Infant crying patterns in the first year: Normal community and clinical findings. Journal of Child Psychology \& Psychiatry, 32, 951-968.

Starkman, M. N. (2006). The terrorist attacks of September 11, 2001, as psychological toxin: Increase in suicide attempts. Journal of Nervous and Mental Disease, 194, 547-550.

Stein, B. D., Jaycox, L. H., Elliott, M. N., Collins, R., Berry, S., Marshall, G. N., \& Schuster, M. A. (2004). The emotional and behavioral impact of terrorism on children: Results from a national survey. Applied Developmental Science, 8, 184-194.

Terr, L., Bloch, D., Michel, B., Shi, H., Reinhardt, J., \& Metayer, S. (1999). Children's symptoms in the wake of Challenger: A field study of distant-traumatic effects and an outline of related conditions. American Journal of Psychiatry, 156, 1536-1544.

Wilson, A. C., Lengua, L. J., Meltzoff, A. N., \& Smith, K. A. (2010). Parenting and temperament prior to September 11, 2001, and parenting specific to $9 / 11$ as predictors of children's posttraumatic stress symptoms following 9/11. Journal of Clinical Child \& Adolescent Psychology, 39, 445-459.

Zeanah, C. H., Larrieu, J. A., Heller, S. S., \& Valliere, J. (2000). Infant-parent relationship assessment. In C. H. Zeanah (Ed.), Handbook of infant mental health (2nd ed., pp. 222-235). New York, NY: Guilford. 